\title{
ERP correlates of item recognition memory: Effects of age and performance
}

\section{Citation}

Wolk, David A., N. Mandu Sen, Hyemi Chong, Jenna L. Riis, Scott M. McGinnis, Phillip J. Holcomb, and Kirk R. Daffner. 2009. "ERP Correlates of Item Recognition Memory: Effects of Age and Performance." Brain Research 1250 (January): 218-231. doi:10.1016/j.brainres.2008.11.014.

\section{Published Version}

10.1016/j.brainres.2008.11.014

\section{Permanent link}

http://nrs.harvard.edu/urn-3:HUL.InstRepos:32521819

\section{Terms of Use}

This article was downloaded from Harvard University's DASH repository, and is made available under the terms and conditions applicable to Other Posted Material, as set forth at http:// nrs.harvard.edu/urn-3:HUL.InstRepos:dash.current.terms-of-use\#LAA

\section{Share Your Story}

The Harvard community has made this article openly available.

Please share how this access benefits you. Submit a story.

Accessibility 


\title{
ERP correlates of item recognition memory: Effects of age and performance
}

\author{
David A. Wolk ${ }^{a,}{ }^{*}$, N. Mandu Sen ${ }^{c}$, Hyemi Chong $^{c}$, Jenna L. Riis ${ }^{c}$, Scott M. McGinnis ${ }^{b, c}$, Phillip \\ J. Holcomb ${ }^{d}$, and Kirk R. Daffnerb,c \\ aDepartment of Neurology, University of Pittsburgh, 3471 Fifth Avenue, Pittsburgh, PA 15217, USA \\ bHarvard Medical School, 25 Shattuck Street, Boston, MA 02115, USA \\ 'Division of Cognitive and Behavioral Neurology, Department of Neurology, Brigham and Women's \\ Hospital, 221 Longwood Avenue, Boston, MA 02115, USA
}

dDepartment of Psychology, Tufts University, MA 02155, USA

\begin{abstract}
Decline in episodic memory is a common feature of healthy aging. Event-related potential (ERP) studies in young adults have consistently reported several modulations thought to index memory retrieval processes, but relatively limited work has explored the impact of aging on them. Further, work with functional imaging has demonstrated differential neural recruitment in elderly subjects depending on their level of cognitive performance which may reflect compensatory or, alternatively, inefficient processing. In the present study we examined the effect of aging and level of performance on both early (FN400, LPC) and later [late frontal effect (LFE)] ERP indices of recognition memory. We found that the FN400 and LPC were absent or attenuated in the older group relative to young adults, but that the LFE was actually increased, analogous to findings in the functional imaging literature. Additionally, the latter effect was most prominent in the poorer performing older participants. These findings suggest that weak memory retrieval supported by earlier ERP modulations, may lead to an enhanced LFE in the service of additional retrieval attempts.
\end{abstract}

\section{Keywords}

Aging; Memory; Event-related potential; FN400; LPC; Late frontal effect

\section{Introduction}

\begin{abstract}
Numerous studies have documented a decline in episodic memory associated with the aging brain. While behavioral studies of memory have offered insight into the underlying nature of this deficit, functional techniques allow for evaluation of component processes in memory retrieval. Exploration of alterations in neural activity during memory retrieval in older adults will likely provide a fuller understanding of the nature of memory loss with healthy aging, as well as potential avenues for intervention.

In particular, a number of studies have suggested that failures of episodic memory with "healthy" aging are due to impairment in controlled processes mediated by the frontal cortex and its connections [for review, see (Buckner, 2004; Hedden and Gabrieli, 2004)]. It is argued
\end{abstract}

(C) 2008 Elsevier B.V. All rights reserved.

*Corresponding author. Fax: 412692 4907. E-mail address: E-mail: wolkda2@upmc.edu (D.A. Wolk). 
that the deficit in frontal systems limits the strategic processing at both encoding and retrieval leading to less successful recapitulation of prior study episodes. Consistent with this notion is work which has found age-associated impairment of the contextual or associative memories of recollection with relative sparing of familiarity (Howard et al., 2006; Yonelinas, 2002). This finding follows from recollection being thought more dependent on controlled processes related to frontal and medial temporal connectivity while familiarity is often conceived of as a more "automatic" form of memory. Alternatively, other studies of aging have suggested a direct relationship between medial temporal dysfunction and memory performance, irrespective of frontal processing. For example, hippocampal atrophy in volumetric structural MRI studies, a surrogate for integrity of this structure, has often been reported to correlate with memory performance in healthy elderly subjects (Van Petten, 2004).

Behavioral memory studies are limited in making such distinctions and determining the component memory processes driving age-associated memory failures and successes. For example, older subjects often perform similarly to young subjects on item memory tasks (Yonelinas, 2002). Nonetheless, alternative neural and cognitive mechanisms may underlie this equivalent performance (e.g. older adults may be more dependent on familiarity than recollection-based retrieval), which could be indexed with functional techniques.

Additionally, recent work, particularly studies with fMRI, has frequently reported alterations in frontal activity during episodic memory tasks in older relative to younger participants [for review, see (Grady, 2008)]. Despite notions of impairment of cognitive control in elderly populations, a number of these studies have reported paradoxical increases in frontal activations (Cabeza et al., 2002; Grady et al., 1995; Gutchess et al., 2005; Logan et al., 2002; Morcom et al., 2007; Velanova et al., 2007). While some of this work suggests that this increased processing may reflect inefficiency, others have argued that it may reflect compensatory mechanisms. It also remains unclear from fMRI studies the nature of the cognitive processing manifested by these activations in light of limited information of their timing. For example, it has been suggested that memory control processes can be divided into those that are pre-retrieval versus those that are post-retrieval (Rugg et al., 2002). Pre-retrieval processes include adopting an appropriate attentional set (retrieval mode), allocating attentional resources (retrieval effort), and adopting a cue processing strategy related to the expectations of the task (retrieval orientation). Post-retrieval processes include the representation and evaluation of retrieved information, as well as the monitoring of retrieval outcome and/or additional strategies needed for successful task completion. In this context, the timing of alterations in frontal activation with aging has implications for the nature of the underlying cognitive process. A more complete understanding of these frontal activations will require greater linkage with this and other models of memory retrieval.

Given its exquisite temporal resolution, event-related potentials (ERPs) have provided some of the strongest support for separable processes underlying recognition memory (Rugg and Curran, 2007). ERPs have generally been employed in recognition memory paradigms in which subjects decide whether test items were on a previous study list. In particular, these studies examine the "old/new" effect, which is the difference between studied items correctly endorsed as 'old' (Hits) and non-studied items correctly endorsed as 'new' (correct rejections; CR's). Generally, Hits are of amore positive voltage than CR's starting about $300 \mathrm{~ms}$ after test item presentation and this effect usually lasts for at least several hundred milliseconds (Rugg, 1995).

More recently, spatially and temporally distinct modulations within the old/new effect have been described and are thought to be associated with different retrieval processes [for review, see (Rugg and Curran, 2007)]. Two early modulations, referred to here as the FN400 and the late posterior component (LPC) old/new effects, have been postulated as correlates of 
familiarity and recollection, respectively. The relationship of the FN400 old/new effect with familiarity is supported by a number of findings, including its modulation by items correctly recognized in the absence of contextual details (Curran, 2004; Duarte et al., 2004; Duzel et al., 1997; Trott et al., 1997;Wolk et al., 2006), non-studied items that are conceptually or perceptually related to studied ones (Curran, 2000; Curran and Cleary, 2003; Nessler et al., 2001), and items studied in a "shallow" manner (Rugg et al., 1998a). Alternatively, the LPC $\mathrm{old} /$ new effect is influenced by retrieval of contextual details and depth of encoding (Curran, 2004; Donaldson and Rugg, 1999; Duzel et al., 1997; Rugg et al., 1998b; Wilding and Rugg, 1996; Woodruff et al., 2006).

Recollection and familiarity have been linked to processing in the medial temporal lobes, including both hippocampal and extra-hippocampal structures (Brown and Aggleton, 2001; Eichenbaum et al., 2007; Squire et al., 2007). While the FN400 and LPC likely are not direct markers of medial temporal activity, these modulations may be dependent on the integrity of these brain regions. For example, amnesia associated with hippocampal pathology results in absence of the LPC old/new effect (Duzel et al., 2001; Olichney et al., 2000). FN400-like effects have been described in the anterior medial temporal lobe, including perirhinal cortex, in human intracranial ERPs (Fernandez and Tendolkar, 2006; Grunwald et al., 1998) and studies using magnetoencephalography [(MEG; (Duzel et al., 2003; Gonsalves et al., 2005)].

A third ERP modulation has also been frequently reported, which we will refer to as the Late Frontal Effect (LFE). This sustained slow-wave can begin as early as $600 \mathrm{~ms}$ after test item presentation and can last $1 \mathrm{~s}$ or longer. As implied by its designation, it tends to be maximal over frontal scalp sites; often preferentially over the right hemisphere. The LFE has been observed in a number of studies and is often attributed to being involved in control-related functions such as post-retrieval monitoring (Allan et al., 2000; Curran et al., 2001; Donaldson and Rugg, 1999; Ranganath and Paller, 2000; Wilding and Rugg, 1997a,b). A related proposal is that this processing may index retrieval effort or directed, additional retrieval attempts when initial representations are impoverished (Ally and Budson, 2007; Ally et al., 2008; Rugg and Allan, 2000). Given its scalp location and putative role, some have speculated that this ERP effect is related to prefrontally-mediated activity, consistent with fMRI retrieval studies [e.g. (Cabeza et al., 2003)].

The integrity of these component processes in aging has been explored to a limited extent and has implications for the nature of age-associated episodic memory loss. Several studies have reported an intact LPC old/new effect in the elderly relative to the young (Li et al., 2004; Mark and Rugg, 1998; Trott et al., 1999; Wegesin et al., 2002). However, these studies specifically examined responses associated with accurate contextual retrieval (e.g., source) and, thus, reflect only those responses associated with recollection. Indeed, studies requiring simple item recognition memory have reported reduction of the LPC old/new effect compared to young controls (Fjell et al., 2005; Rugg et al., 1997; Swick and Knight, 1997; Walhovd et al., 2006). Examination of item recognition success may be a more "unbiased" sample of memory retrieval, as familiarity and/or recollection can support performance. Thus, when retrieval success is not limited to responses associated with contextual retrieval, recollection appears generally reduced in older subjects echoing behavioral studies of aging (Davidson and Glisky, 2002; Howard et al., 2006; Parkin and Walter, 1992). Few studies have examined the integrity of the FN400 in aging and, thus far, the results have been inconsistent (Ally et al., 2008; Duarte et al., 2006; Trott et al., 1999). Several studies have evaluated the LFE in aging, and, here too, the results are mixed with some studies showing preservation of the effect ( $\mathrm{Li}$ et al., 2004; Mark and Rugg, 1998) and others showing attenuation (Trott et al., 1999; Wegesin et al., 2002). These studies have examined the LFE only in the context of source retrieval. Nonetheless, it remains uncertain why the results have varied, but are likely due to stimulus and subject-related factors. In particular, differences in the characteristics of the older 
populations studied, particularly with regard to cognitive capacity (high versus low performing), could influence these findings [see (Riis et al., 2008)].

As noted above, several functional imaging studies have reported paradoxical increases in frontal activity associated with healthy aging (Cabeza et al., 2002; Daselaar et al., 2003; Grady et al., 1995; Gutchess et al., 2005; Logan et al., 2002; Madden et al., 1999; Morcom et al., 2007; Park et al., 2003). Based on subject performance, claims as to whether these activations are related to compensation or inefficiency have been proposed. While we have reported increased P300 amplitudes associated with high relative to average performing older adults on tasks of novelty processing (Daffner et al., 2006; Riis et al., 2008), little work has explored the relationship between performance and ERP old/new effects in aging [see (Duarte et al., 2006; Walhovd et al., 2006) for two recent examples]. Such work may help to address whether age-related changes reflect compensatory or dysfunctional neural operations. One significant advantage of ERPs over other functional imaging techniques is its excellent temporal resolution, on the order of milliseconds, which may allow for better classification of the role played by the frontal activations reported in the fMRI literature (e.g. preversus post-retrieval processes).

In the present study, healthy young and old adults performed a relatively difficult, but straightforward, item (word) recognition memory task while recording ERPs. We compared FN400, LPC, and LFE old/new differences between the two groups to gain insight into the relative weighting of component memory processes supporting item recognition judgments between the two groups. Additionally, we were interested in how performance modulated these ERP old/new effects, particularly the LFE, in the older group and whether evidence of compensation or inefficiency would be seen with ERPs as reported in the fMRI literature. To do so, we compared older participants who were divided into high and low performers based on their discrimination performance for the present experimental task.

\section{Results}

\subsection{Participant characteristics}

Standard psychometric testing results are presented in Table 1. The sample represents a welleducated and high IQ group of participants. As can be seen in the table, there were some tests in which differences between the two groups reached statistical significance. As estimated by the AMNART, IQ was somewhat higher in the older group while memory measures and category generation favored the younger group. Nonetheless, the older group performed quite similarly to their younger controls and well within the normal range for this population.

\subsection{Behavioral data}

Both groups performed the task reasonably well without evidence of floor or ceiling effects (see Table 2). Younger participants had a higher proportion of both Hits (.77 vs. .74, young vs. old) and CR's (.79 vs. .72, young vs old). The difference in Hits did not reach statistical significance $[t(50)=.79, p>0.1]$, but the difference in CR's did $[t(50)=2.25, p<0.05]$. In other words, older adults made more false alarms (FA) than their young counterparts. To compare overall performance, a simple measure of discrimination was used (Hits - FA). The young controls had better discrimination than the older group [.57 vs. .46 , respectively, $t(50)=2.27$, $p<0.05]$.

\subsection{ERP analysis - young versus old}

2.3.1. Description of waveforms-Fig. 1 displays ERPs for Hits and CR's in both age groups (see Fig. 3a for scalp topographies of the old/new effect). In the young subjects, Hits were associated with a more positive potential than CR's starting around $300 \mathrm{~ms}$ after stimulus 
onset. This difference appeared broadly across the scalp initially, but eventually became maximal at more posterior sites and ended by around $700 \mathrm{~ms}$. Over the next $500 \mathrm{~ms}$ there was little difference between these responses with, if anything, CR's exhibiting a more positive voltage than Hits. Near the end of the recording epoch ( 1200 ms) a frontally maximal positivity for Hits relative to CR's was seen.

The older participants had a very different relationship between Hits and CR's. There was little evidence of differences in the early intervals that traditionally encompass the FN400 and LPC old/new effect (300-700 ms). However, beginning around $800 \mathrm{~ms}$ and lasting until the end of the recording epoch, Hits were of a more positive voltage than CR's. This difference appeared maximal at frontal scalp sites.

The following analyses were pursued to investigate the apparent differences between the young and old subjects. For each interval of interest, ANOVAs employing the between-subjects factor of age (young, old) and the within-subjects factors of old/new (o/n; Hits, CR's), anteriorposterior (a-p; anterior, posterior), and laterality (left, midline, right) were calculated. We were most interested in interactions involving age and response type, which would indicate differences in the old/new effect. Main effects or interactions which did not include these factors, as well as non-significant results, will not be discussed unless of theoretical interest. To further explore interactions, subsidiary ANOVAs were employed.

2.3.2. 300-500 ms-In the epoch traditionally associated with the FN400 old/new effect, a main effect of $\mathrm{o} / \mathrm{n}\left[F(1,50)=11.81, p<.01, \eta^{2}=.19\right]$ was seen due to an overall higher voltage for Hits relative to CR's. Importantly, an o/n $\times$ age interaction approached significance $[F(1,50)$ $\left.=3.68, p=.06, \eta^{2}=.07\right]$, reflecting a greater old/new effect in the young subjects. This interaction was further modified by laterality $\left[F(2,100)=3.70, p<.05, \eta^{2}=.07\right]$, as midline sites had a greater old/new effect relative to more lateral ones in the young subjects.

These results were further explored with separate $\mathrm{o} / \mathrm{n} \times \mathrm{a}-\mathrm{p} \times$ laterality ANOVAs in the two age groups. Confirming the findings above, young subjects had a main effect of o/n $[F(1,25)$ $\left.=13.55, p<.01, \eta^{2}=.35\right]$, an $\mathrm{o} / \mathrm{n} \times$ laterality interaction $\left[F(2,50)=12.00, p<.001, \eta^{2}=.32\right]$, and an $\mathrm{o} / \mathrm{n} \times$ laterality $\times \mathrm{a}-\mathrm{p}$ interaction $\left[F(2,50)=6.54, p<.01, \eta^{2}=.21\right]$. These reflect that the FN400 was more attenuated for Hits than CR's, particularly at midline and posterior sites. Older participants did not have a main effect of o/n or its interaction with any other factor $(p ' s>0.1)$.

2.3.3. 500-700 ms-In the temporal window of the LPC, an effect of o/n $[F(1,50)=9.93$, $\left.p<.01, \eta^{2}=.17\right], \mathrm{o} / \mathrm{n} \times$ age $\left[F(1,50)=10.71, p<.01, \eta^{2}=.18\right]$, and o/n $\times$ age $\times$ laterality $[F(2,100)$ $\left.=7.59, p<0.01, \eta^{2}=.13\right]$ were all significant. These results are consistent with amuch larger LPC old/new effect in the young participants, particularly at midline sites. The main effect of o/n was further modified by laterality $\left[F(2,100)=3.70, p<0.05, \eta^{2}=.07\right]$, a-p $[F(2,100)=8.94$, $\left.p<0.01, \eta^{2}=.15\right]$, and a-p $\times$ laterality $\left[F(2,100)=8.22, p<0.01, \eta^{2}=.14\right]$. These interactions were due to the greatest difference between Hits and CR's being at posterior midline sites.

To further explore the interaction with age, follow-up ANOVAs were performed. In the young, there were significant effects of o/n $\left[F(1,25)=34.23, p<.001, \eta^{2}=.56\right], \mathrm{o} / \mathrm{n} \times$ laterality $[F(2,50)$ $\left.=9.87, p<.001, \eta^{2}=.28\right]$ and $\mathrm{o} / \mathrm{n} \times$ laterality $\times \mathrm{a}-\mathrm{p}\left[F(1,25)=12.67, p<.001, \eta^{2}=.34\right]$. In old adults, only an $\mathrm{o} / \mathrm{n} \times \mathrm{a}-\mathrm{p}$ interaction reached significance $\left[F(2,50)=5.46, p<.05, \eta^{2}=.18\right]$ due to Hits being less positive the CR's over anterior scalp sites, but with the opposite pattern, if anything, at posterior sites.

2.3.4. 800-1000 ms-There were no significant effects of o/n or its interactions with other factors (all $p^{\prime} \mathrm{s}>.1$ ). It is worth noting that there was a trend for an $\mathrm{o} / \mathrm{n} \times$ age interaction $[F(1,50)$ 
$=2.22, p=.14]$ reflecting the beginning of the LFE (Hits more positive than CR's) in the older participants, but not present in the young.

2.3.5. 1000-1200 ms-An o/n $\times$ age interaction was significant $\left[F(1,50)=4.11, p<.05, \eta^{2}=\right.$. 08 ] due to evolution of the anterior old/new effect in the older subjects, but not observed in the young. Follow-up ANOVAs in the young subjects did not reveal an effect of $\mathrm{o} / \mathrm{n}$ or interactions with this factor $\left(p^{\prime} \mathrm{s}>.1\right)$ while in the old subjects $\mathrm{o} / \mathrm{n} \times \mathrm{a}-\mathrm{p}$ approached significance $[F(1,25)=$ $\left.2.95, p<.1, \eta^{2}=.11\right]$ reflecting that Hits were more positive than CR's maximally at frontal sites.

2.3.6. 1200-1500 ms-A main effect of o/n reached significance $[F(1,50)=7.38, p<.01$, $\left.\eta^{2}=.13\right]$ with Hits more positive than CR's. There were no interactions of o/n with age $\left(F^{\prime} \mathrm{s}<1.0\right.$, $\left.p^{\prime} \mathrm{s}>.1\right)$. An interaction of o/n $\times \mathrm{a}-\mathrm{p} \times$ laterality approached significance $[F(2,100)=2.69, p=$. $08, \eta^{2}=.05$ ] reflecting the o/n effect being larger and more evenly distributed at anterior sites while the effect was largest at midline posterior sites.

2.3.7. Early vs. Late ERP effects-As is apparent from above, the young group demonstrated large early old/new effects (300-700 ms) while these effects were markedly diminished in the older participants. The opposite pattern appeared to hold for the earlier portion of the temporal epoch usually associated with the late frontal effect (800-1200 ms). To further explore this dissociation, difference waves (Hits minus CR's)were computed for the early (300-700ms) and late epochs ( $800-1200 \mathrm{~ms})$ at $\mathrm{Fz}$ and Pz. These difference waves were submitted to an age (young, old) $\times$ epoch $(300-700 \mathrm{~ms}, 800-1200 \mathrm{~ms}) \times$ site $(\mathrm{Fz}, \mathrm{Pz})$ ANOVA. A significant interaction of age $\times$ epoch $\left[F(1,50)=9.8, p<.01, \eta^{2}=.16\right]$ was found, reflecting the dissociation across age groups of the early and later old/new effects.

\subsection{High versus low performing older adults}

We were interested in determining the relationship of performance on the present item memory task and the ERP old/new effect. To do so, we divided the older group into high and low performers by conducting a median split of the 26 older participants based on their discrimination (Hits - False Alarms). Of note, the same procedure was carried out for the young controls, but did not yield significant differences between the groups, and this data will not be presented here.

2.4.1. Behavioral data-Demographic and psychometric data of the two groups formed by this median split are displayed in Table 3 . These groups did not differ in age or education $\left[t^{\prime}<<1.0\right]$. Although on some of the standard psychometric tests the high performers appeared superior, including CERAD word list encoding and recall, none of these differences was near significant. The only test that approached significance was category fluency $[t(24)=1.9, p=$. 07].

Performance on the experimental memory task for the high and low performers is displayed in Table 2. The high performers had a higher proportion of Hits $[t(24)=2.9, p<.01]$ and CR's $[t(24)=2.8, p<.01]$ than the low performers. As expected discrimination differed significantly $[t(24)=6.6, p<.001]$ between the two groups. It is worth pointing out that the high performers did not differ from the young group in discrimination [.57 vs. .60, respectively; $t<1.0]$.

\subsubsection{ERP analysis-high versus low performing older subjects}

2.4.2.1. Description of waveforms: ERPs for Hits and CR's for both groups are presented in Fig. 2 (see Fig. $3 \mathrm{~b}$ for scalp topographies of the old/new effect). In the lower performing group, there was little evidence of early (300-700 ms) old/new effects, but a large frontally maximal effect is seen starting around approximately $900 \mathrm{~ms}$ that was sustained throughout the remainder of the recording epoch. For the high performers, a somewhat different pattern was 
seen. There appears to be a small old/new effect at posterior sites in the temporal epoch of the LPC (500-700 ms). There is also a frontally maximal effect beginning around $800 \mathrm{~ms}$, but offsetting around 1200 to $1300 \mathrm{~ms}$.

To further investigate these differences, ANOVAs employing the between-subjects factor of performance (high, low) and the within-subjects factors of o/n (Hits, CR's), anterior-posterior (a-p; anterior, posterior), and laterality (left, midline, right) were calculated. Intervals of interest were the same as above. To further explore interactions of theoretical interest, subsidiary ANOVAs were also employed. Effects that did not involve interactions with performance and $\mathrm{o} / \mathrm{n}$, or that were reported above, will not be repeated.

2.4.2.2.300-500 ms: No interaction with group approached significance $\left(F^{\prime} s \leq 1.0, p^{\prime} \mathrm{s}>0.1\right)$.

2.4.2.3. 500-700 ms: A near significant interaction of performance with $\mathrm{o} / \mathrm{n} \times \mathrm{a}-\mathrm{p} \times$ laterality $\left[F(2,48)=3.0, p=.07, \eta^{2}=.11\right]$ was seen in this epoch. This interaction appeared to reflect a posterior old/new effect in the high performers and a more right-hemisphere effect in the low performers. To follow-up on this interaction and the observation of an LPC effect in the high performers, separate ANOVAs were performed for each group. In the high performers, an o/ $\mathrm{n} \times \mathrm{a}-\mathrm{p}$ interaction was observed $\left[F(1,12)=8.1, p<.05, \eta^{2}=.40\right]$ consistent with the presence of an LPC old/new effect. For the low performers, an o/n $\times$ a-p $\times$ laterality interaction $[F(2,24)$ $\left.=5.1, p<.05, \eta^{2}=.30\right]$ was seen due to a left hemisphere old/new effect with CR's exhibiting a more positive voltage than Hits at anterior sites.

2.4.2.4. 800-1000 ms: There was a trend for an interaction of performance $\times \mathrm{o} / \mathrm{n} \times \mathrm{a}-\mathrm{p} \times$ laterality $\left[F(2,48)=2.6, p<.10, \eta^{2}=.10\right]$. This appeared due to Hits having a more positive voltage than CR's more over left hemisphere, anterior scalp sites in the high performing group while this effect was greater over right hemisphere, anterior sites in the low performing group. No other interactions of o/n with performance were significant $\left(F^{\prime} \mathrm{s} \leq 1.2, p^{\prime} \mathrm{s}>.10\right)$.

2.4.2.5. 1000-1200 ms: A performance $\times \mathrm{o} / \mathrm{n} \times \mathrm{a}-\mathrm{p}$ interaction was near significance $[F(2,48)$ $=3.5, p=.07, \eta^{2}=.13$ ] due to a larger anterior difference between Hits and CR's (Hits>CR's) in the low performers compared to the high performers. Follow-up ANOVAs revealed an o/n $\times$ a-p interaction $\left[F(1,12)=4.9, p<.05, \eta^{2}=.29\right]$ in the low performers reflecting the frontally maximal old/new effect, or LFE. There were no significant effects of o/n or its interaction with other factors in the high performing group $\left(F^{\prime} s<1.0, p^{\prime} \mathrm{s}>1\right)$.

2.4.2.6. 1200-1500 ms: A main effect of o/n $\left[F(1,24)=5.2, p<.05, \eta^{2}=.18\right]$ and an $\mathrm{o} / \mathrm{n} \times$ performance interaction $\left[F(1,24)=5.6, p<.05, \eta^{2}=.19\right]$ was significant. These effects reflect that Hits were more positive than CR's, and that this effect was only present in the low performers. There was an additional significant interaction of $\mathrm{o} / \mathrm{n} \times \mathrm{a}-\mathrm{p} \times$ performance $[F$ $(2,48)=9.0, p<.01, \eta^{2}=.27$ ] due to the old/new effect being maximum at anterior scalp sites in the low performers.

Follow-up ANOVAs for both groups were explored. For the low performers, a main effect of $\mathrm{o} / \mathrm{n}\left[F(1,12)=8.5, p<.05, \eta^{2}=.42\right]$ and $\mathrm{o} / \mathrm{n} \times \mathrm{a}-\mathrm{p}$ interaction $\left[F(1,12)=6.5, p<.05, \eta^{2}=.35\right]$ was observed due to Hits being more positive than CR's maximally at anterior sites, consistent with an LFE. There were no effects of o/n or interactions with other factors in the high performing group $\left(F^{\prime} \mathrm{s}<2.5, p^{\prime} \mathrm{s}>.10\right)$.

\section{Discussion}

The current study examined the ERP correlates of item memory retrieval on a relatively difficult item recognition memory task. Early ERP old/new effects (300-700 ms) were present in the 
young whereas they were markedly diminished in the older subjects. However, a frontally maximal old/new effect, or LFE, was seen in the older participants starting around $900 \mathrm{~ms}$ and lasting until the end of the recording epoch, but was not present in the young controls until around 1200 to $1300 \mathrm{~ms}$. Further, this late effect was most prominent amongst the poorer performing older subjects relative to those who performed well on the task. We will discuss these findings in turn and their relationship to the existing ERP and functional imaging literature on aging.

\subsection{Early effects (300-700 ms)}

These data are distinct from some recent ERP studies of recognition memory which have reported relative sparing of early old/new effects, particularly the LPC, but with, decreased or equivalent LFE's (Li et al., 2004; Mark and Rugg, 1998; Trott et al., 1997; Trott et al., 1999). The question then is how to place the current results in the context of this literature. One important point is that while several studies have demonstrated intact early old/new effects in older participants (Li et al., 2004; Mark and Rugg, 1998; Trott et al., 1997; Trott et al., 1999), a number of studies, focusing on the LPC old/new effect, have not. For example, several earlier studies using continuous recognition memory paradigms found diminished or absent early old/ new effects even after relatively short lags (<60 s) (Rugg et al., 1997; Swick and Knight, 1997). In a more recent cross-sectional investigation, participants varying in age across the lifespan performed an item recognition memory task (Fjell et al., 2005; Walhovd et al., 2006). These investigators reported that age was negatively correlated with the LPC old/new effect and the topography tended to involve more anterior scalp sites in the older subjects. Other work has found a somewhat diminished effect over posterior left hemisphere sites (the region in which the LPC is usually maximal), but a comparable, relative to young, effect over right hemisphere scalp sites (Li et al., 2004; Swick et al., 2006). In the latter two reports, a left hemisphere negative wave was speculated as the cause of the diminished LPC. No such negative wave was seen in the present study as an explanation for the reduced early old/new effects. Regardless, the present data are by no means an anomaly with regard to this ERP effect.

Several potential explanations may account for this variability across studies. The present study involved an intentional encoding task - subjects were asked to simply try to remember the words for a later test. In two of the studies in which the LPC old/new effect was spared, subjects performed an incidental encoding task requiring semantic elaboration (Li et al., 2004; Mark and Rugg, 1998). The studies by Trott and colleagues, which also demonstrated an intact parietal old/new effect for older participants, utilized an intentional task; however, study words were presented in the context of sentences, which may produce more naturally enhanced semantic elaboration (Trott et al., 1997; Trott et al., 1999). Much work has supported the notion that older subjects perform more poorly than younger ones on intentional rather than incidental encoding tasks due to less spontaneous instantiation of appropriate encoding strategies (Glisky et al., 2001; Logan et al., 2002; Naveh-Benjamin, 2000; Naveh-Benjamin et al., 2007). In particular, 'deep', semantic encoding is thought to support later memory retrieval. Thus, the reduced early old/new effects in the current study may reflect a weaker memory trace in the older participants due to differences in encoding strategies. Indeed, other work has demonstrated that the LPC is dependent on the depth of encoding (Curran, 2004; Rugg et al., 2000; Rugg et al., 1998a).

Perhaps a more important difference between the current paradigm and studies demonstrating an LPC old/new effect inert to aging is that the latter tasks all involved source memory (Li et al., 2004; Mark and Rugg, 1998; Trott et al., 1997; Trott et al., 1999). Source memory tasks require retrieval of associative details, which has been linked to the amplitude of the LPC (Donaldson and Rugg, 1998; Wilding and Rugg, 1996, 1997a). Both the encoding and retrieval conditions of source memory tasks promote the formation and retrieval of such bound details. 
In an item memory task, such as the present one, older subjects may be less likely to spontaneously appropriate available resources to the encoding and retrieval of associative details than in a task in which it is explicitly required (e.g., a source memory task). As noted above, young subjects may use more effective encoding and retrieval strategies regardless of the nature of the task. Thus, age differences in associative retrieval as marked by the LPC may be greatest in item recognition memory tasks in which such retrieval is not explicitly required. Future work could address differences in LPC response related to encoding and task requirements in older populations.

Additionally, correct source judgments require retrieval of associative details and provide a more select sample of "hits" that are specifically associated with recollection than are items correctly recognized on an item recognition memory task. Thus, it stands to reason that regardless of age, the LPC old/new effect is more likely to be present in source tasks if this component indexes retrieval of contextual details. Alternatively, correct responses on item tasks represent a mixture of recollection and familiarity. Interestingly, the paradigms that have employed item memory tasks in aging studies have largely found a diminished LPC old/new effect as found here (Ally et al., 2008; Rugg et al., 1997; Swick and Knight, 1997; Walhovd et al., 2006), suggesting that item recognition may be associated with less detailed retrieval in older than younger subjects.

Finally, study material, task difficulty, study-test delay, and heterogeneity in the study populations may further account for differences in the presence of the LPC old/new effect in studies of aging. For example, a recent report suggested that early ERP effects (both FN400 and LPC) are diminished in older populations when studying word stimuli, but were relatively intact for pictures (Ally et al., 2008). This result was reflected by behavioral performance on the two tasks; better performance for pictures than words. Similarly, we found that the higher performing older subjects demonstrated an LPC old/new effect not seen in the low performers.

If detailed memories, as reflected by the LPC old/new effect, are reduced in the older subjects, the expectation would be that familiarity is driving their reasonably accurate memory performance. Such a hypothesis, as noted above, is suggested by behavioral studies and some fMRI work (Daselaar et al., 2006). However, the FN400 old/new effect (usually 300-500 ms) also appeared diminished in the older participants. The FN400 effect has received relatively little consideration in studies of aging, and the results have been mixed. One study that specifically looked at correlates of familiarity did not find evidence of modulation of this component in older subjects (Duarte et al., 2006). Another study found the absence of this effect specific to words, but not picture stimuli (Ally et al., 2008). Alternatively, other studies have not found this effect for pictures (Gutchess et al., 2007b; Li et al., 2004), but have for words (Trott et al., 1999). Given the relative sparing of familiarity in older subjects reported in the behavioral literature (Davidson and Glisky, 2002; Howard et al., 2006; Jacoby, 1999; Yonelinas, 2002), these results are difficult to reconcile with the notion that the FN400 indexes this memory process in older adults. It is certainly possible that different ERP modulations underlie familiarity in older relative to younger subjects. Future investigation should more directly address the nature and functional significance of familiarity correlates in aging.

\subsection{Late effects}

Of most interest, we found that while early ERP old/new effects were markedly reduced in the old relative to the young participants, the opposite pattern emerged for the LFE. This finding was revealed in the age $\times$ epoch (300-700 ms, 800-1200 ms) interaction. The LFE has been postulated to represent pre-frontal activity in the service of post-retrieval monitoring or evaluation (Nessler et al., 2001; Ranganath and Paller, 2000; Wilding and Rugg, 1997b). It has also been suggested that the activity may index retrieval effort or controlled processes related to directing additional retrieval attempts when initial representations are impoverished (Ally 
and Budson, 2007; Ally et al., 2008; Rugg and Allan, 2000). Prior studies of aging have reported this effect either to be diminished (Senkfor and Van Petten, 1998; Trott et al., 1999; Wegesin et al., 2002) or preserved in older subjects (Ally et al., 2008; Li et al., 2004; Mark and Rugg, 1998).

The current result differs from these prior studies by demonstrating an augmentation of this late old/new effect. While the literature is limited, and most prior studies of item memory did not assess these late effects, to our knowledge this is the first ERP study to produce such a finding, which is more closely aligned with results from the functional imaging literature. A number of fMRI studies using either event-related or blocked designs have reported age-related increases in cortical recruitment for memory tasks, either at encoding or retrieval (Cabeza et al., 2002; Daselaar et al., 2003; Grady et al., 1995; Gutchess et al., 2005; Logan et al., 2002; Madden et al., 1999; Morcom et al., 2007; Park et al., 2003). In particular, this increased recruitment in elderly subjects often involves prefrontal cortex. In some cases the additional activity is a manifestation of increased recruitment of homologous contralateral regions to that recruited in the young (loss of functional lateralization), but in other cases is a reflection of recruitment in different regions or the same regions with increased intensity (Cabeza et al., 2002; Morcom et al., 2007).

The dissociation of a reduction in the early ERP old/new effects, thought to reflect medial temporal function, with an increase in the temporally later LFE, which may index prefrontal function, is reminiscent of results reported in an fMRI study of memory encoding (Gutchess et al., 2005). Gutchess and colleagues found reduction in medial temporal activation associated with subsequent memory success in older subjects compared to younger ones, but the opposite pattern with regard to dorsolateral prefrontal cortex activation. Further, the activation in these two regions were inversely related in the older participants. The prefrontal activity may then reflect compensation for deficient medial temporal processing. Likewise, here, impoverished reinstatement of the prior study episode bymedial temporal structures (reflected in the reduced LPC and FN400 old/new effects) is associated with an earlier and more sustained LFE. It is worth noting that these investigators recapitulated this study with ERPs and did not find increased frontal activation (Gutchess et al., 2007b). However, they did not examine time intervals beyond $900 \mathrm{~ms}$. Our results are also similar to a recent source memory study in the ERP literature (Swick et al., 2006). Swick and colleagues found an attenuated LPC in both old subjects and those with frontal lobe lesions relative to young adults. However, the old adults demonstrated an additional left anterior old/new effect from 600 to $1200 \mathrm{~ms}$, which was not present in the young or frontal lobe patients. This activity (opposite in polarity from the current findings), may also represent compensatory activity dependent on intact prefrontal functioning.

The LFE old/new effect had an opposite polarity for the older versus younger subjects between 800-1200 ms. This cross-over phenomenon has also been recently reported in the fMRI literature (Morcom et al., 2007). Morcom and colleagues reported areas, including in the prefrontal cortex, in which hit activation was greater than correct rejections for older subjects, but the opposite was true for the young. The more generalized greater activation for hits relative to correct rejections in the older subjects may reflect a dedifferentiation of neural recruitment with aging.

The present ERP results add to the functional imaging literature by providing information on the timing of the increased cortical recruitment. In addition, ERPs are not confounded by potential age-related effects on the properties of the bold signal in fMRI [see (Handwerker et al., 2007)], which has critical implications for its functional significance. For example, if the increased prefrontal activation represented a pre-retrieval phenomenon, such as a consequence of retrieval effort, one would expect to observe increased activity throughout the recording epoch. Our finding of this activity only after failure to instantiate robust early old/new effects 
suggests that processing reflected by the LFE in the older cohort may be related to additional retrieval attempts in the context of a weak memory trace. This result is consistent with the notion that the LFE may index controlled processing in the service of these additional attempts (Ally et al., 2008). Thus, although control mechanisms may be generally impaired as a result of aging, impacting the effectiveness of encoding and pre-retrieval processes, this impairment leads to an increase in the retrieval demands of the task and need for later controlled activity. As such, the older subjects, particularly those who perform the poorest, may need to compensate by instantiating additional, later controlled processes. Velanova and colleagues provided a similar interpretation in a related fMRI study of item recognition memory in which older subjects demonstrated greater frontal activation in a "high control" task (Velanova et al., 2007). In this study, the high control task was defined by task difficulty (high control items were studied once while low control items were studied multiple times). These investigators examined the time course of the enhanced frontal effect and found that it appeared to occur later than parietal activations typically associated with memory retrieval. Thus, these authors attributed the frontal activation to a late selection process (post-retrieval) to compensate for poorer early selection (pre-retrieval).

Notably, at about $1200 \mathrm{~ms}$ the young group also began to display a frontally-maximal old/new effect. As participants are asked to refrain from responding until a signal at $1500 \mathrm{~ms}$, it is difficult to know whether this activity is related to retrieval or perhaps preparing for the upcoming response. Given the timing and presence of robust early ERP old/new modulations, it seems unlikely that this effect reflects the same processing as the LFE seen in the older participants, which begins about $300 \mathrm{~ms}$ prior to that of the young.

\subsection{Performance effects}

There is a need in the ERP memory and aging literature to examine the effects of performance on the neural underpinnings of memory processing (Friedman, 2003). Such analyses may provide additional insight into the nature of age-associated memory impairment. For example, study of performance effects in functional imaging studies has generated hypotheses regarding the nature of increased recruitment in older subjects (Cabeza et al., 2002; Daselaar et al., 2003; Rosen et al., 2002). Much of this work has centered on whether the increased activity is a reflection of compensation or inefficient processing. If enhanced recruitment is observed in higher performing subjects, some have argued that this is a reflection of compensation (Cabeza et al., 2002; Daselaar et al., 2006; Davis et al., 2008; Gutchess et al., 2007a; Rosen et al., 2002). For example, Cabeza and colleagues found that low performing older adults recruited right prefrontal cortex to a similar extent as young subjects on a source memory task. Consistent with the notion of compensation, high performing older adults had an additional, more symmetric recruitment of prefrontal cortex (Cabeza et al., 2002). Alternatively, if the poorer performers are the ones with increased activation, this activity is then often considered related to inefficient processing (Colcombe et al., 2005; Zarahn et al., 2007). Colcombe and colleagues not only found that older adults who performed poorer on a task of inhibition had higher prefrontal cortex activation relative to those that performed better, but that they also had lower white matter density. Other work has also found that white matter integrity may be related to increased activation in older adults suggesting that this activation may reflect this pathological change (Persson et al., 2006). It should, of course, be noted that these constructs are not orthogonal. For example, greater inefficiency at one stage of processing may be associated with compensatory activation at a later stage. Further, increased activation in poorer performers could still support performance of the task in a compensatory manner that is unnecessary in the higher performers (Zarahn et al., 2007).

While we found that the older group had an earlier and larger late frontal effect than the young group, this was most pronounced in the low performers. Such a result, based on the logic of 
above, may be consistent with the notion that this activity reflects inefficient processing. Further, while the effect was maximal at frontal sites, its broad distribution may be consistent with the idea that dedifferentiation, or breakdown of neural specialization, may drive this inefficiency.

However, we favor that this activity still may reflect some degree of compensation. The high performing older adults exhibited some evidence of an LPC old/new effect which was not present for the low performers. As noted above, the late frontal activity may be involved in directing additional retrieval attempts when memory is weak. Thus, the difference between the high and low performers may be driven in part by the poorer initial retrieval of the latter group and reflect compensatory activity, akin to the fMRI findings of Velanova et al. noted above (Velanova et al., 2007). This interpretation is tentative as we did not find a significant inverse correlation between the early and late old/new effects in the older participants. This could be due to a number of factors including the noise of the ERP response or limited variance of the early ERP effects which were near floor in the older adults.

The present data offers one of the first attempts at examining ERP correlates of recognition memory based on performance in older adults. Two other recent studies have also examined the relationship of memory accuracy in aging with ERP correlates of retrieval success (Duarte et al., 2006; Walhovd et al., 2006). Walhovd and colleagues studied subjects with a broadly distributed age range in an item memory task and focused on the LPC old/new effect. In general, they found that the amplitude of the effect decreased with age and that the distribution was more anterior. Interestingly, those who performed most poorly on the task had the largest anterior old/new difference. This greater dependence on more anterior effects in the poorer performers is similar to the current findings. Duarte et al. also found a late frontal effect (700$1200 \mathrm{~ms}$ ) only present in the poor performing group, also akin to the present results. However, this old/new effect had the opposite polarity of the current one. The authors suggested that this activity may represent non-selective recruitment in the poorer performing participants.

It should at least be noted that the nature of the activations can vary between groups, both with regard to the underlying processes being supported and the significance of increases or decreases. For example, increases in activation in young adults could represent inefficiency rather than compensation. It is also worth noting that comparisons between groups (e.g., younger to older adults) in ERP and fMRI studies may be confounded by disparities in performance (Li et al., 2004; Morcom et al., 2007). As performance declines on a recognition test, there is likely a greater number of both hits and correct rejections that are associated with "lucky guesses," which effectively dilutes both of these response categories diminishing the magnitude of old/new effects. Such a confound may be relevant for the decreased early effects observed in the low performing old group relative to their high performing and young counterparts. However, increases in the old/new effect associated with poorer performing groups are not subject to this criticism, as lucky guesses would tend to blunt these responses. Thus, if anything, the increase late frontal old/new effect of the poor performing old group is likely to be an underestimation of the magnitude of this effect.

\subsection{Conclusion}

We have found on an item recognition memory task that early ERP old/new effects (FN400 and LPC) are diminished in old relative to young adults. In contradistinction, the LFE was earlier and more robust in the older population. Further, it was of greatest amplitude in those who performed most poorly and had the weakest early old/new effects. These results suggest that aging may result in poorer initial retrieval of items supported by medial temporal structures. The increased frontal activity in older adults may then reflect additional retrieval related processing which is instantiated most prominently in those with the weakest memory. 


\section{Experimental procedures}

\subsection{Participants}

Informed consent was obtained for 27 young subjects ( 17 female; mean age 22.8 years old; mean education: 15.7 years) and 28 older subjects (19 Female; mean age: 73.6 years; mean education: 16.3 years). Two of the older controls and 1 younger control were not included in the analysis due to technical failures of the recording. Participants were recruited through community announcements. After completing informed consent, participants underwent an evaluation that included a medical, neurological, and psychiatric history; a formal neurological examination; and a screening battery of standard neuropsychological tests.

Younger subjects were between 18-30 years old and older subjects between 65-85 years old. Participants had to be English speaking, have $\geq 12$ years of education, have a Mini-Mental Status Exam Score (Folstein et al., 1975) of $\geq 26$, and be right handed. Subjects were excluded if they had a history of a central nervous system diseases or major psychiatric disorders based on the Diagnostic and Statistical Manual of Mental Disorders, Fourth Edition criteria (Association, 1994), a history of clinically significant medical diseases, corrected visual acuity worse than 20/40, or focal abnormalities on neurological examination consistent with a lesion of the central nervous system. Participation was voluntary and subjects were compensated \$25 per hour. The study was approved by the Institutional Review Board of Brigham and Women's Hospital, Boston, MA.

IQ was estimated in all participants based on the American Modification of the National Adult Reading Test [AMNART; (Ryan and Paola, 1992)]. In addition, all participants completed the following standard psychometric tests: (1) Controlled Oral Word Association Test [COWAT; (Ivnik et al., 1996)]; (2) category fluency [animals, (Spreen and Strauss, 1998)]; (3) Visual Retention Test (Benton et al., 1994); (4) Trail Making Test A and B (Reitan, 1958); and (5) Consortium to Establish a Registry for Alzheimer's Disease (CERAD) Word List Memory test [memory, recall, and recognition; (Morris et al., 1989)]. To further assess that the older adults did not have evidence of an incipient dementia, the following additional tests were administered: (1) Mini-Mental Status Exam (Folstein et al., 1975); (2) a 15-item version of the Boston Naming Test [BNT; (Kaplan et al., 1983)]; and (3) Digit Span subtest of the Wechsler Adult Intelligence Scale III (Wechsler, 1997).

\subsection{Materials and design}

Stimuli consisted of 480 words ( 5 to 8 letters; mean Thorndike-Lorge frequency: 221.8) collected from the University of Western Australia MRC Psycholinguistic database (http://www.psy.uwa.edu.au/MRCDataBase/UWA_mrc.htm). The words were divided into two lists of 240 words; words from one list served as study items and words from the other were foils, counterbalanced across subjects. There were three study-test blocks with 80 words at study and 96 words at test (half studied and half unstudied). In each study block, 12 words were presented in a larger, color font while the rest were in white; all were on a black background. At test, 24 words were presented in a larger, color font (half studied; half unstudied) and 72 in white (half studied; half unstudied). Results from the color words were not analyzed here and were included in the paradigm to test the 'isolate' or 'von Restorff' effect in aging (Hunt and Lamb, 2001; Restorff, 1933). Thus, the present analysis includes recognition judgments on 108 studied and 108 unstudied words.

\subsection{Procedure}

All participants were instructed to study the words for a later memory task. They were told that some items would be in white while others would be in color, but that they should try to remember all items for the subsequent test. In the study phase, a "+" was presented for 1500 
ms followed by a blank screen for $250 \mathrm{~ms}$. The study word was then presented for $1000 \mathrm{~ms}$. After a $250 \mathrm{~ms}$ blank screen, the cycle repeated. For each block, the test phase would immediately follow each study phase. Subjects were instructed to decide whether each test word was studied previously ("Old" response) or was not ("New" response). After a $500 \mathrm{~ms}$ fixation "+", test words were presented for $1000 \mathrm{~ms}$ followed by a blank screen for $500 \mathrm{~ms}$. Then an "Old or New?" prompt would appear on the screen. To reduce EEG eye-movement and response-related artifact, subjects were asked to refrain from blinking or responding until this prompt appeared [this procedure has been used in several previous ERP studies (Curran and Cleary, 2003; Curran et al., 2006; Wolk et al., 2004)]. After the "Old or New?" prompt, subjects verbally gave their answer to the experimenter who then entered the response with a key press. Participants were able to rest between each of the three study-test blocks.

\subsection{Electrophysiological recording}

ERPs were recorded from 35 active tin electrodes that were held in place on the scalp by an electrode cap (Electro-Cap International, Eaton, OH, USA). Electrode locations were based on the International 10-20 system and were arranged in 5 columns, each with 7 antero-posterior sites. The midline sites were $\mathrm{FPz}, \mathrm{Fz}, \mathrm{FCz}, \mathrm{Cz}, \mathrm{CPz}, \mathrm{Pz}$, and $\mathrm{Oz}$. There were two inner lateral columns that included FP1/2, F3/4, FC3/4, C3/4, CP3/4, P3/4, O1/2 and two outer lateral columns that included AF7/8, F7/8, FT7/8, T7/8, TP7/8, P7/8, PO7/8. All sites were referenced to the left mastoid. An electrode was placed below the left eye (LE) for detection of eye blinks and vertical eye movements (electrical activity at LE was compared to an electrode above the eye to monitor for these eye movements). Another electrode was placed at the right lateral canthus (referenced to an electrode at the left lateral canthus) to detect horizontal eye movements. The EEG was amplified by an SA Instrumentation system, using a band filter with negative $3-\mathrm{dB}$ cutoffs of 0.01 to $40 \mathrm{~Hz}$ and was continuously digitized $(100 \mathrm{~Hz})$.

\subsection{ERP analysis}

Continuous EEG data were divided off-line into epochs beginning $200 \mathrm{~ms}$ prior to test item presentation and ending $1500 \mathrm{~ms}$ after test item presentation. Trials with amplifier blocking or eye movements were excluded; blinks were corrected (Dale, 1994). Separate ERPs were calculated for 'Hits' (studied items given an "Old” response) and 'Correct Rejections' (CR's; unstudied items given a "New" response). For the young subjects, a mean number of 81 (SD: 12.4) and 79 (SD: 13.3) trials were averaged for Hits and CR's, respectively. For the older participants, a mean number of 77 (SD: 16.2) and 77 (SD: 11.5) trials were averaged for Hits and CR's, respectively. Mean amplitude (relative to a $100 \mathrm{~ms}$ pre-stimulus baseline) was calculated for both response types at each electrode to capture the FN400 (300-500 ms) and LPC (500-800 ms). In addition, the following epochs were analyzed to evaluate late frontal effects based on visual inspection of the waveforms in the two groups: 800-1000 ms, 1000$1200 \mathrm{~ms}, 1200-1500 \mathrm{~ms}$. In cases of electrode failure, voltages were calculated as the average of two contiguous electrodes.

In general, the intervals of interest were analyzed using analysis of variance (ANOVA), with age (young, old) as the between-subjects variable and old/new (o/n; Hits, CR's), anteriorposterior (a-p; anterior, posterior), and laterality (left, midline, right) as the within-subjects variables. Electrodes were divided into 6 groups for these analyses (left anterior: AF7, FP1, F7, F3; middle anterior: FPz, Fz; right anterior: AF8, FP2, F8, F4; left posterior: TP7, CP3, P7, P3; middle posterior: $\mathrm{CPz}, \mathrm{Pz}$; right posterior: TP8, CP4, P8, P4). This distribution of electrodes was used to capture the apparent ERP effects based on visual inspection for the intervals of interest. It is worth noting that ANOVAs using the full electrode array produced very similar results. To examine ERP differences between high and low performing older adults, additional ANOVAs involving factors of performance (high, low), o/n, a-p, and laterality were performed at each of the intervals of interest. The Green-house-Geisser 
correction procedure was used for repeated measures factors with greater than one numerator degree of freedom. Effect size $\left(\eta^{2}\right)$ of main effects of o/n and interactions with age or performance were reported. For brevity, main effects of location (either laterality or a-p) and interactions that were either non-significant or did not involve age and o/n were not reported unless of theoretical significance. All $p$-values reported were 2-tailed and were considered significant if they were less than 0.05 .

\section{Acknowledgments}

We thank Eric Signoff for assistance in manuscript preparation. The research was supported by the National Institute of Aging K23 AG028018 and the Harvard Center for Neurodegeneration and Repair.

\section{REFERENCES}

Allan K, Robb WGK, Rugg MD. The effect of encoding manipulations on neural correlates of episodic retrieval. Neuropsychologia 2000;38:1188-1205. [PubMed: 10838153]

Ally BA, Budson AE. The worth of pictures: using high density event-related potentials to understand the memorial power of pictures and the dynamics of recognition memory. Neuroimage 2007;35(1): 378-395. [PubMed: 17207639]

Ally BA, Waring JD, Beth EH, McKeever JD, Milberg WP, Budson AE. Aging memory for pictures: Using high-density event-related potentials to understand the effect of aging on the picture superiority effect. Neuropsychologia 2008;46(2):679-689. [PubMed: 17981307]

Association, AP. Diagnostic and Statistical Manual of Mental Disorders. Vol. fourth ed.. Washington, D.C: American Psychiatric Association; 1994.

Benton, AL.; Sivab, AB.; deS Hamsher, K.; Varney, NR.; Spreen, O. Contributions to Neuropsychological Assessment. Vol. second ed.. New York: Oxford University Press; 1994.

Brown CM, Aggleton JP. Recognition memory: what are the roles of the perirhinal cortex and hippocampus? Nat. Rev. Neurosci 2001;2:51-61. [PubMed: 11253359]

Buckner RL. Memory and executive function in aging and AD: multiple factors that cause decline and reserve factors that compensate. Neuron 2004;44(1):195-208. [PubMed: 15450170]

Cabeza R, Anderson ND, Locantore JK, McIntosh AR. Aging gracefully: compensatory brain activity in high-performing older adults. Neuroimage 2002;17(3):1394-1402. [PubMed: 12414279]

Cabeza R, Locantore JK, Anderson ND. Lateralization of prefrontal activity during episodic memory retrieval: evidence for the production-monitoring hypothesis. J. Cogn. Neurosci 2003;15(2):249-259. [PubMed: 12676062]

Colcombe SJ, Kramer AF, Erickson KI, Scalf P. The implications of cortical recruitment and brain morphology for individual differences in inhibitory function in aging humans. Psychol. Aging 2005;20(3):363-375. [PubMed: 16248697]

Curran T. Brain Potentials of recollection and familiarity. Mem. Cog 2000;28:923-938.

Curran T. Effects of attention and confidence on the hypothesized ERP correlates of recollection and familiarity. Neuropsychologia 2004;42:1088-1106. [PubMed: 15093148]

Curran T, Cleary AM. Using ERPs to dissociate recollection from familiarity in picture recognition. Cogn. Brain Res 2003;15(2):191-205.

Curran T, Schacter DL, Johnson MK, Spinks R. Brain potentials reflect behavioral differences in true and false recognition. J. Cogn. Neurosci 2001;13(2):201-216. [PubMed: 11244546]

Curran T, DeBuse C, Woroch B, Hirshman E. Combined pharmacological and electrophysiological dissociation of familiarity and recollection. J. Neurosci 2006;26(7):1979-1985. [PubMed: 16481430]

Daffner KR, Ryan KK, Williams DM, Budson AE, Rentz DM, Wolk DA, et al. In creased responsiveness to novelty is associated with successful cognitive aging. J. Cogn. Neurosci 2006;18(10):1759-1773. [PubMed: 17014379]

Dale, AM. Dissertation Abstracts International. Vol. 5507B. 1994. Source localization and spatial discriminant analysis of event-related potentials: Linear approaches (brain cortical surface); p. 2559 
Daselaar SM, Veltman DJ, Rombouts SA, Raaijmakers JG, Jonker C. Neuroanatomical correlates of episodic encoding and retrieval in young and elderly subjects. Brain 2003;126(Pt 1):43-56. [PubMed: 12477696]

Daselaar SM, Fleck MS, Dobbins IG, Madden DJ, Cabeza R. Effects of healthy aging on hippocampal and rhinal memory functions: an event-related fMRI study. Cereb. Cortex 2006;16(12):1771-1782. [PubMed: 16421332]

Davidson PS, Glisky EL. Neuropsychological correlates of recollection and familiarity in normal aging. Cogn. Affect. Behav. Neurosci 2002;2(2):174-186. [PubMed: 12455684]

Davis SW, Dennis NA, Daselaar SM, Fleck MS, Cabeza R. Que PASA? The posterior-anterior shift in aging. Cereb. Cortex 2008;18(5):1201-1209. [PubMed: 17925295]

Donaldson DI, Rugg MD. Recognition memory for new associations: electrophysiological evidence for the role of recollection. Neuropsychologia 1998;36(5):377-395. [PubMed: 9699947]

Donaldson DI, Rugg MD. Event-related potential studies of associative recognition and recall: electrophysiological evidence for context dependent retrieval processes. Cogn. Brain Res 1999;8(1): $1-16$.

Duarte A, Ranganath C, Winward L, Hayward D, Knight RT. Dissociable neural correlates for familiarity and recollection during the encoding and retrieval of pictures. Cogn. Brain Res 2004;18(3):255-272.

Duarte A, Ranganath C, Trujillo C, Knight RT. Intact recollection memory in high-performing older adults: ERP and behavioral evidence. J. Cogn. Neurosci 2006;18(1):33-47. [PubMed: 16417681]

Duzel E, Yonelinas AP, Mangun GR, Heinze H, Tulving E. Event-related potential correlates of two states of conscious awareness in memory. Proc. Natl. Acad. Sci. U. S. A 1997;94:5973-5978. [PubMed: 9159185]

Duzel E, Vargha-Khadem F, Heinze HJ, Mishkin M. Brain activity evidence for recognition without recollection after early hippocampal damage. Proc. Natl. Acad. Sci. U. S. A 2001;98(14):8101-8106. [PubMed: 11438748]

Duzel E, Habib R, Schott B, Schoenfeld A, LoBaugh N, McIntosh A, et al. A multivariate, spatiotemporal analysis of electromagnetic time-frequency data of recognition memory. Neuroimage 2003;18:185197. [PubMed: 12595175]

Eichenbaum H, Yonelinas AP, Ranganath C. The medial temporal lobe and recognition memory. Annu. Rev. Neurosci 2007;30:123-152. [PubMed: 17417939]

Fernandez G, Tendolkar I. The rhinal cortex: 'gatekeeper' of the declarative memory system. Trends Cogn. Sci 2006;10(8):358-362. [PubMed: 16843039]

Fjell AM, Walhovd KB, Reinvang I. Age-differences in verbal recognition memory revealed by ERP. Clin. EEG Neurosci 2005;36(3):176-187. [PubMed: 16128153]

Folstein MF, Folstein SE, McHugh PR. "Mini-mental state". a practical method for grading the cognitive state of patients for the clinician. J. Psychiatr. Res 1975;12(3):189-198. [PubMed: 1202204]

Friedman D. Cognition and aging: a highly selective overview of event-related potential (ERP) data. J. Clin. Exp. Neuropsychol 2003;25(5):702-720. [PubMed: 12815507]

Glisky EL, Rubin SR, Davidson PS. Source memory in older adults: an encoding or retrieval problem? J. Exp. Psychol. Learn. Mem. Cogn 2001;27(5):1131-1146. [PubMed: 11550742]

Gonsalves BD, Kahn I, Curran T, Norman KA, Wagner AD. Memory strength and repetition suppression: multimodal imaging of medial temporal cortical contributions to recognition. Neuron 2005;47(5): 751-761. [PubMed: 16129403]

Grady CL. Cognitive neuroscience of aging. Ann. N. Y. Acad. Sci 2008;1124:127-144. [PubMed: 18400928]

Grady CL, McIntosh AR, Horwitz B, Maisog JM, Ungerleider LG, Mentis MJ, et al. Age-related reductions in human recognition memory due to impaired encoding. Science 1995;269(5221):218221. [PubMed: 7618082]

Grunwald T, Lehnertz K, Heinze HJ, Helmstaedter C, Elger CE. Verbal novelty detection within the human hippocampus proper. Proc. Natl. Acad. Sci. U. S. A 1998;95(6):3193-3197. [PubMed: 9501239]

Gutchess AH, Welsh RC, Hedden T, Bangert A, Minear M, Liu LL, et al. Aging and the neural correlates of successful picture encoding: frontal activations compensate for decreased medial-temporal activity. J. Cogn. Neurosci 2005;17(1):84-96. [PubMed: 15701241] 
Gutchess AH, Hebrank A, Sutton BP, Leshikar E, Chee MW, Tan JC, et al. Contextual interference in recognition memory with age. Neuroimage 2007a;35(3):1338-1347. [PubMed: 17355910]

Gutchess AH, Ieuji Y, Federmeier KD. Event-related potentials reveal age differences in the encoding and recognition of scenes. J. Cogn. Neurosci 2007b;19(7):1089-1103. [PubMed: 17583986]

Handwerker DA, Gazzaley A, Inglis BA, D'Esposito M. Reducing vascular variability of fMRI data across aging populations using a breathholding task. Hum. Brain Mapp 2007;28(9):846-859. [PubMed: 17094119]

Hedden T, Gabrieli JD. Insights into the ageing mind: a view from cognitive neuroscience. Nat. Rev. Neurosci 2004;5(2):87-96. [PubMed: 14735112]

Howard MW, Bessette-Symons B, Zhang Y, Hoyer WJ. Aging selectively impairs recollection in recognition memory for pictures: evidence from modeling and receiver operating characteristic curves. Psychol. Aging 2006;21(1):96-106. [PubMed: 16594795]

Hunt RR, Lamb CA. What causes the isolation effect? J. Exp. Psychol. Learn. Mem. Cogn 2001;27(6): 1359-1366. [PubMed: 11713872]

Ivnik RJ, Malec JF, Smith GE, Tangalos EG, Petersen RC. Neuropsychological tests' norms above age 55: COWAT, BNT, MAE Token, WRAT-R Reading, AMNART, STROOP, TMT, and JLO. Clin. Neuropsychol 1996;10:262-278.

Jacoby LL. Ironic effects of repetition: measuring age-related differences in memory. J. Exper. Psychol. Learn. Mem. Cogn 1999;25:3-22. [PubMed: 9949705]

Kaplan, E.; Goodglass, H.; Weintraub, S. The Boston Naming Test. Philadelphia: Lea and Feibiger; 1983.

Li J, Morcom AM, Rugg MD. The effects of age on the neural correlates of successful episodic retrieval: an ERP study. Cogn. Affect. Behav. Neurosci 2004;4(3):279-293. [PubMed: 15535164]

Logan JM, Sanders AL, Snyder AZ, Morris JC, Buckner RL. Under-recruitment and nonselective recruitment: dissociable neural mechanisms associated with aging. Neuron 2002;33(5):827-840. [PubMed: 11879658]

Madden DJ, Gottlob LR, Denny LL, Turkington TG, Provenzale JM, Hawk TC, et al. Aging and recognition memory: changes in regional cerebral blood flow associated with components of reaction time distributions. J. Cogn. Neurosci 1999;11(5):511-520. [PubMed: 10511640]

Mark RE, Rugg MD. Age effects on brain activity associated with episodic memory retrieval. An electrophysiological study. Brain 1998;121(5):861-873. [PubMed: 9619190]

Morcom AM, Li J, Rugg MD. Age effects on the neural correlates of episodic retrieval: increased cortical recruitment with matched performance. Cereb. Cortex 2007;17(11):2491-2506. [PubMed: 17204820]

Morris JC, Heyman A, Mohs RC, Hughes JP, van Belle G, Fillenbaum G, et al. The Consortium to Establish a Registry for Alzheimer's Disease (CERAD). Part I. Clinical and neuropsychological assessment of Alzheimer's disease. Neurology 1989;39(9):1159-1165. [PubMed: 2771064]

Naveh-Benjamin M. Adult age differences in memory performance: tests of an associative deficit hypothesis. J. Exp. Psychol. Learn. Mem. Cogn 2000;26(5):1170-1187. [PubMed: 11009251]

Naveh-Benjamin M, Brav TK, Levy O. The associative memory deficit of older adults: the role of strategy utilization. Psychol. Aging 2007;22(1):202-208. [PubMed: 17385995]

Nessler D, Mecklinger A, Penney TB. Event related brain potentials and illusory memories: the effects of differential encoding. Cogn. Brain Res 2001;10(3):283-301.

Olichney JM, Petten CV, Paller KA, Salmon DP, Iragui VJ, Kutas M. Word repetition in amnesia: electrophysiological measures of impaired and spared memory. Brain 2000;123(1948-1963)

Park DC, Welsh RC, Marshuetz C, Gutchess AH, Mikels J, Polk TA, et al. Working memory for complex scenes: age differences in frontal and hippocampal activations. J. Cogn. Neurosci 2003;15(8):11221134. [PubMed: 14709231]

Parkin AJ, Walter BM. Recollective experience, normal aging, and frontal dysfunction. Psychol. Aging 1992;7:290-298. [PubMed: 1610518]

Persson J, Nyberg L, Lind J, Larsson A, Nilsson LG, Ingvar M, et al. Structure-function correlates of cognitive decline in aging. Cereb. Cortex 2006;16(7):907-915. [PubMed: 16162855]

Ranganath C, Paller KA. Neural correlates of memory retrieval and evaluation. Cogn. Brain Res 2000;9:209-222. 
Reitan R. Validity of the trail making test as an indicator of organic brain disease. Percept. Mot. Skills 1958;8:271-276.

Restorff, v. Uber die Wirkung von Beriechsblidungen im Spurenfeld. Psychol. Res 1933;18:299-343.

Riis JL, Chong H, Ryan KK, Wolk DA, Rentz DM, Holcomb PJ, et al. Compensatory neural activity distinguishes different patterns of normal cognitive aging. Neuroimage 2008;39(1):441-454. [PubMed: 17931892]

Rosen AC, Prull MW, O'Hara R, Race EA, Desmond JE, Glover GH, et al. Variable effects of aging on frontal lobe contributions to memory. Neuroreport 2002;13(18):2425-2428. [PubMed: 12499842]

Rugg, MD. Event-related potentials studies of human memory. In: Gazzaniga, M., editor. The Cognitive Neurosciences. Cambridge, MA: MIT Press; 1995. p. 789-803.

Rugg, MD.; Allan, K. Electrophysiology of memory retrieval. In: Gazzaniga, MS., editor. The New Cognitive Neurosciences. Cambridge: MIT Press; 2000. p. 805-816.

Rugg MD, Curran T. Event-related potentials and recognition memory. Trends Cogn. Sci 2007;11(6): 251-257. [PubMed: 17481940]

Rugg MD, Mark RE, Gilchrist J, Roberts RC. ERP repetition effects in indirect and direct tasks: effects of age and interitem lag. Psychophysiology 1997;34(5):572-586. [PubMed: 9299912]

Rugg MD, Mark RE, Walla P, Schloerscheidt AM, Birch CS, Allan K. Dissociation of the neural correlates of implicit and explicit memory. Nature 1998a;392(6676):595-598. [PubMed: 9560154]

Rugg MD, Schloerscheidt AM, Mark RE. An electrophysiological comparison of two indices of recollection. J. Mem. Lang 1998b;39(47-69)

Rugg MD, Allan K, Birch CS. Electrophysiological evidence for the modulation of retrieval orientation by depth of study processing. J. Cogn. Neurosci 2000;12:664-678. [PubMed: 10936918]

Rugg, MD.; Herron, JE.; Morcom, AM. Electrophysiological studies of retrieval processing. In: Squire, LR.; Schacter, DL., editors. Neuropsychology of Memory. Vol. third ed.. New York: The Guilford Press; 2002. p. 154-165.

Ryan J, Paola A. A screening procedure for estimating premorbid intelligence in the elderly. Clin. Neuropsychol 1992;6:53-62.

Senkfor AJ, Van Petten C. Who said what? An event-related potential investigation of source and item memory. J. Exp. Psychol. Learn. Mem. Cogn 1998;24(4):1005-1025. [PubMed: 9699305]

Spreen, O.; Strauss, E. A Compendium of Neuropsychological Tests: Administration, Norms, and Commentatory. Vol. second ed.. New York: Oxford University Press; 1998.

Squire LR, Wixted JT, Clark RE. Recognition memory and the medial temporal lobe: a new perspective. Nat. Rev. Neurosci 2007;8(11):872-883. [PubMed: 17948032]

Swick D, Knight RT. Event-related potentials differentiate the effects of aging on word and nonword repetition in explicit and implicit memory tasks. J. Exp. Psychol. Learn. Mem. Cogn 1997;23(1): 123-142. [PubMed: 9028023]

Swick D, Senkfor AJ, Van Petten C. Source memory retrieval is affected by aging and prefrontal lesions: behavioral and ERP evidence. Brain Res 2006;1107(1):161-176. [PubMed: 16828722]

Trott CT, Friedman D, Ritter W, Fabiani M. Item and source memory: differential age effects revealed by event-related potentials. Neuroreport 1997;8(15):3373-3378. [PubMed: 9351675]

Trott CT, Friedman D, Ritter W, Fabiani M, Snodgrass JG. Episodic priming and memory for temporal source: event-related potentials reveal age-related differences in prefrontal functioning. Psychol. Aging 1999;14(3):390-413. [PubMed: 10509695]

Van Petten C. Relationship between hippocampal volume and memory ability in healthy individuals across the lifespan: review and meta-analysis. Neuropsychologia 2004;42(10):1394-1413. [PubMed: 15193947]

Velanova K, Lustig C, Jacoby LL, Buckner RL. Evidence for frontally mediated controlled processing differences in older adults. Cereb. Cortex 2007;17(5):1033-1046. [PubMed: 16774962]

Walhovd KB, Fjell AM, Reinvang I, Lundervold A, Fischl B, Quinn BT, et al. The functional and structural significance of the frontal shift in the old/new ERP effect. Brain Res 2006;1081(1):156170. [PubMed: 16542641]

Wechsler, D. Administration and Scoring Manual. Vol. third ed.. San Antonio: The Psychological Corporation; 1997. Wechsler Adult Intelligence Scale. WAIS-III.. 
Wegesin DJ, Friedman D, Varughese N, Stern Y. Age-related changes in source memory retrieval: an ERP replication and extension. Cogn. Brain Res 2002;13(3):323-338.

Wilding EL, Rugg MD. An event-related potential study of recognition memory with and without retrieval of source. Brain 1996;119(3):889-905. [PubMed: 8673500]

Wilding EL, Rugg MD. An event-related potential study of memory for words spoken aloud or heard. Neuropsychologia 1997a;35(9):1185-1195. [PubMed: 9364489]

Wilding EL, Rugg MD. Event-related potentials and the recognition memory exclusion task. Neuropsychologia 1997b;35(2):119-128. [PubMed: 9025116]

Wolk DA, Schacter DL, Berman AR, Holcomb PJ, Daffner KR, Budson AE. An electrophysiological investigation of the relationship between conceptual fluency and familiarity. Neurosci. Lett 2004;369 (2):150-155. [PubMed: 15450686]

Wolk DA, Schacter DL, Lygizos M, Sen NM, Holcomb PJ, Daffner KR, et al. ERP correlates of recognition memory: effects of retention interval and false alarms. Brain Res 2006;1096(1):148-162. [PubMed: 16769040]

Woodruff CC, Hayama HR, Rugg MD. Electrophysiological dissociation of the neural correlates of recollection and familiarity. Brain Res 2006;1100(1):125-135. [PubMed: 16774746]

Yonelinas A. The nature of recollection and familiarity: A review of 30 years of research. J. Mem. Lang 2002;46:441-517.

Zarahn E, Rakitin B, Abela D, Flynn J, Stern Y. Age-related changes in brain activation during a delayed item recognition task. Neurobiol. Aging 2007;28(5):784-798. [PubMed: 16621168] 


\section{Young}

Old

F1<smiles>[Te][Te]</smiles>

FP

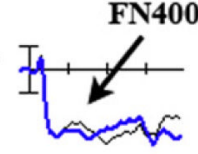

F3

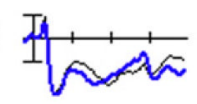

C3

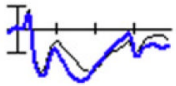

3 In

01 Then

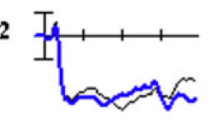

Fz

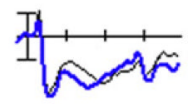

CA
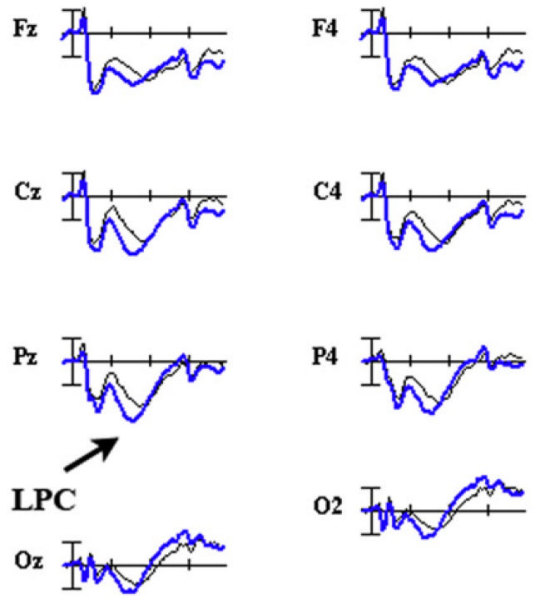

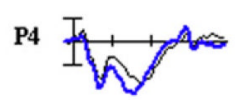

02

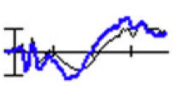

$3 \mathrm{uV}$

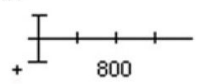

F1

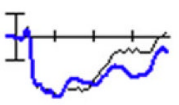

FP

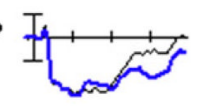

F3

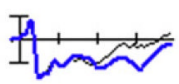

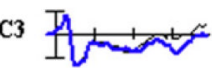

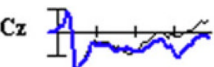

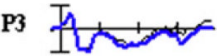

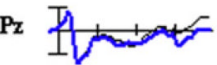

01 for

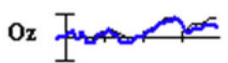

F2

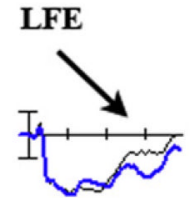

F4

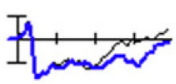

$\mathrm{C} 4$

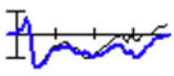

P4

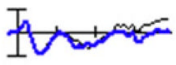

02

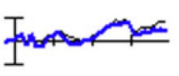

Fig. 1.

Hits and correct rejections: young and old. Grand average ERP plots for hits (blue) and correct rejections (black) at select electrode sites for young (left) and old (right) participants. Arrows point to the FN400, LPC, and LFE. 


\section{Low Performers}

F1

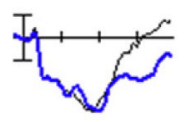

F3<smiles>CCCCCN1CCCC1</smiles>

c3 It

P3

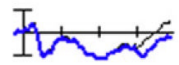

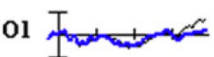

FP

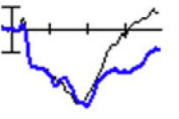

Fz

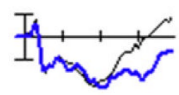

$\mathrm{Cz}$

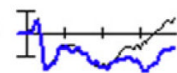

Pz

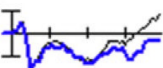

$0 \mathrm{x}$

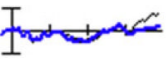

F2

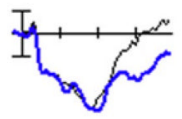

F4

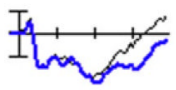

c4 It ,

P4

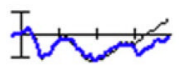

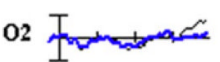

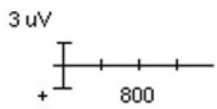

High Performers

FP I

F2

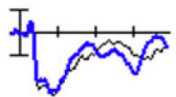

Fz

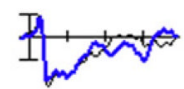

F4

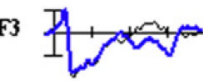

C3 草地

$\mathrm{Cx}$ 苦然然

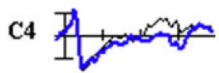

P3

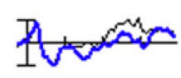

Px 苚

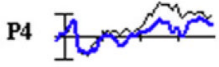

01

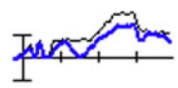

ox Thx 1,

02 和乐,

Fig. 2.

Hits and correct rejections: high and low performing old. Grand average ERP plots for hits (blue) and correct rejections (black) at select electrode sites for low (left) and high (right) performing old participants. 
a.

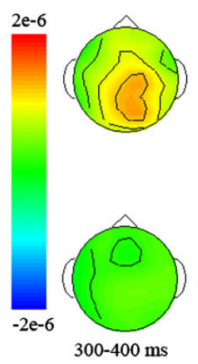

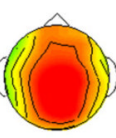
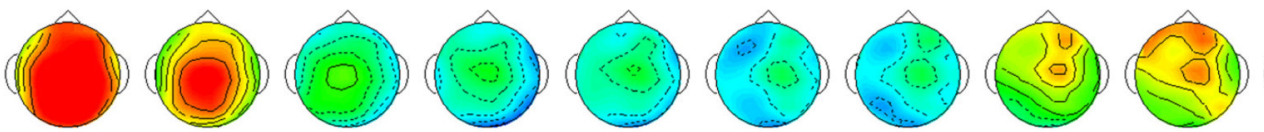

OLD

b.
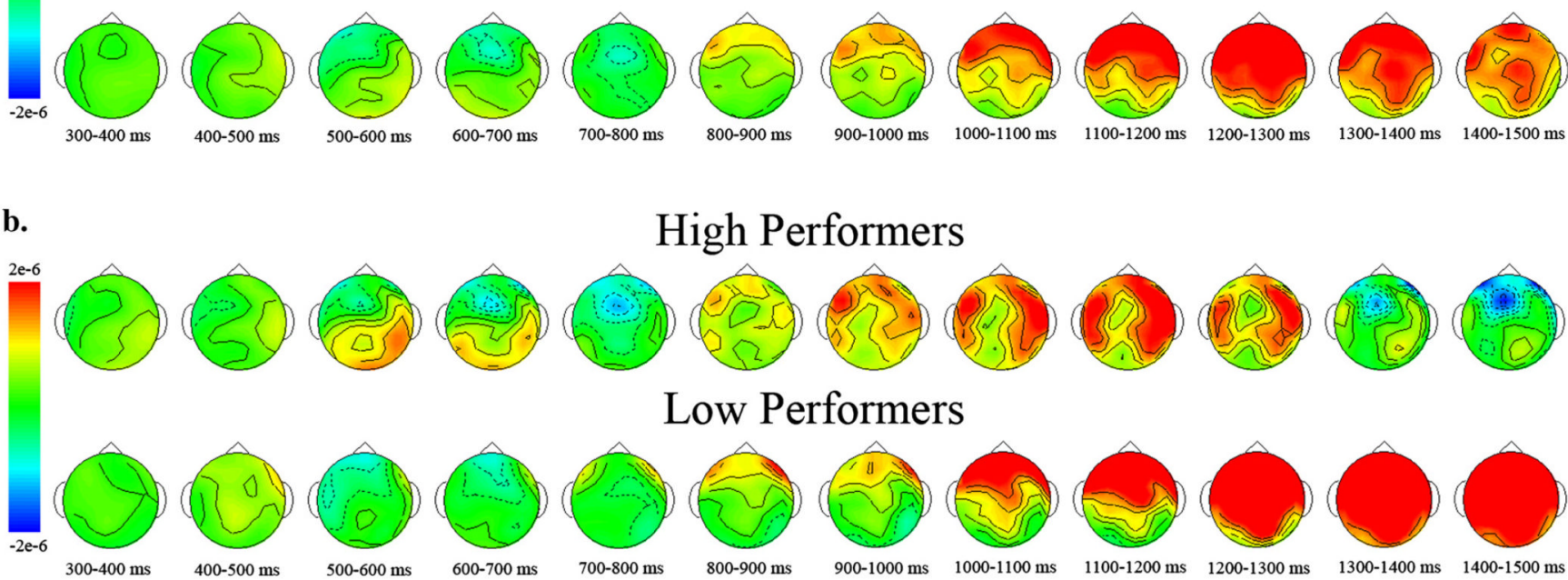

High Performers
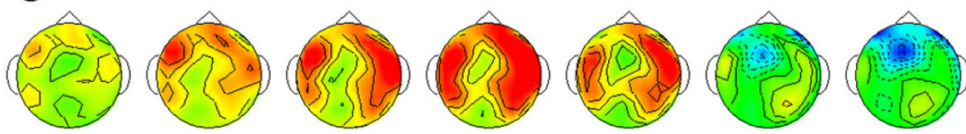

\section{Low Performers}
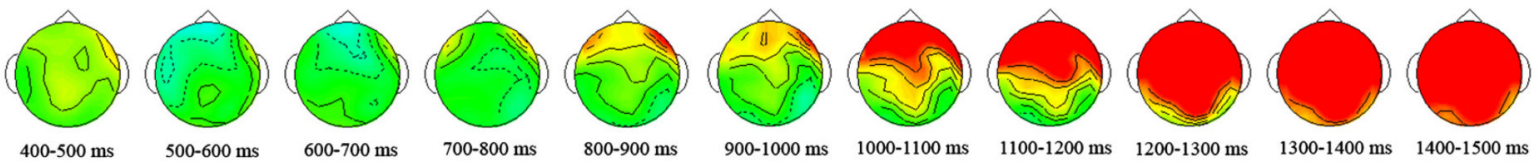

Fig. 3.

Topographic distributions. Topographic distributions of ERP differences between hits and correct rejections at $100 \mathrm{~ms}$ intervals. (a) Shows young and old topographies, while in (b) the old group is divided into high and low performers. 
Table 1

Demographic and psychometric data on young and old groups

\begin{tabular}{|c|c|c|c|c|}
\hline & \multicolumn{2}{|c|}{ Young $(n=26)$} & \multicolumn{2}{|c|}{ Old $(n=26)$} \\
\hline & Average & SD & Average & SD \\
\hline Age (yrs) & 22.8 & 2.4 & $73.6^{a}$ & 6.2 \\
\hline Education (yrs) & 15.7 & 2.1 & 16.3 & 2.4 \\
\hline Sex (number female) & 16 & & 19 & \\
\hline AMNART estimated IQ & 120.4 & 5.4 & $125.4^{a}$ & 5.4 \\
\hline MMSE & & & 29.4 & 0.6 \\
\hline CERAD encoding & 24.8 & 3.2 & $21.9^{a}$ & 3.9 \\
\hline CERAD recall & 8.2 & 1.6 & $7.0^{a}$ & 1.4 \\
\hline CERAD recognition & 9.84 & 0.4 & 9.65 & 0.7 \\
\hline COWAT & 48.1 & 9.7 & 50.9 & 12.5 \\
\hline Category (animals) & 23.2 & 5.1 & $20.5^{a}$ & 3.8 \\
\hline Trails A (seconds) & 26.9 & 8.4 & $35.0^{a}$ & 10.1 \\
\hline Trails B (seconds) & 53.2 & 13.1 & $82.1^{a}$ & 23.1 \\
\hline BNT-15 item & & & 14.9 & 0.3 \\
\hline Digit span forwards & & & 11.6 & 1.7 \\
\hline Digit span backwards & & & 8.0 & 2.4 \\
\hline
\end{tabular}


Table 2

Proportion hits, correct rejections, and discrimination

\begin{tabular}{llll}
\hline & Hits & CR's & Discrimination \\
\hline Young & $.77(.12)$ & $.79(.11)$ & $.57(.15)$ \\
Old & $.74(.15)$ & $.72(.13)^{a}$ & $.46(.17)^{a}$ \\
High performers & $.82(.11)$ & $.78(.12)$ & $.60(.11)$ \\
Low performers & $.67(.15)^{b}$ & $.66(.11)^{b}$ & $.33(.10)^{b}$ \\
& & & \\
\hline
\end{tabular}

$a_{\mathrm{p}<0.05 \text { for old versus young participants. }}$

$b_{\mathrm{p}<0.01 \text { for high versus low performers. }}$ 
Table 3

Demographic and psychometric data on high and low performing old participants

\begin{tabular}{|c|c|c|c|c|}
\hline \multirow[t]{2}{*}{ Test } & \multicolumn{2}{|c|}{$\begin{array}{c}\text { High performers } \\
\qquad(n=13)\end{array}$} & \multicolumn{2}{|c|}{$\begin{array}{c}\text { Low performers } \\
\qquad(n=13)\end{array}$} \\
\hline & Average & SD & Average & SD \\
\hline Age (yrs) & 73.8 & 5.6 & 73.5 & 6.9 \\
\hline Education (yrs) & 16.5 & 2.1 & 16.0 & 2.7 \\
\hline Sex (\# females) & 10 & & 9 & \\
\hline AMNART estimated IQ & 126.2 & 3.5 & 124.8 & 6.9 \\
\hline MMSE & 29.5 & 0.5 & 29.4 & 0.8 \\
\hline CERAD encoding & 22.8 & 3.8 & 21.0 & 3.9 \\
\hline CERAD recall & 7.3 & 1.8 & 6.8 & 0.8 \\
\hline CERAD recognition & 9.6 & 0.7 & 9.7 & 0.9 \\
\hline COWAT & 53.4 & 10.7 & 48.5 & 14.0 \\
\hline Category (animals) & 21.8 & 4.2 & 19.2 & 2.8 \\
\hline Trails A & 36.8 & 11.4 & 34.1 & 9.1 \\
\hline Trails B & 82.4 & 24.0 & 83.1 & 24.2 \\
\hline BNT-15 item & 14.9 & 0.3 & 14.9 & 0.3 \\
\hline Digit span forwards & 12.0 & 2.1 & 10.6 & 3.1 \\
\hline Digit span backwards & 8.4 & 2.1 & 7.8 & 2.7 \\
\hline
\end{tabular}

